\title{
Número necessário de experimentos para a comparação de cultivares de feijão
}

\author{
Number of necessary experiments for the comparison in common bean cultivars
}

Alberto Cargnelutti Filho ${ }^{1}$ Nerinéia Dalfollo Ribeiro ${ }^{2}$ Evandro Jost $^{3}$

\section{RESUMO}

\begin{abstract}
$O$ objetivo deste trabalho foi determinar o número de medições (experimentos) necessários à predição do desempenho de cultivares de feijão (Phaseolus vulgaris $L$.). Quatorze cultivares de feijão foram avaliadas em nove experimentos conduzidos em Santa Maria, Estado do Rio Grande do Sul (latitude $29^{\circ} 42^{\prime}$ S, longitude 53 $49^{\prime} \mathrm{W}$ e $95 \mathrm{~m}$ de altitude), nos anos agrícolas de 2000/2001 a 2004/2005. As avaliações foram constituídas por produtividade de grãos, número de vagens por planta, número de sementes por vagem, massa de cem grãos, população final de plantas, número de dias da emergência ao florescimento, número de dias da emergência à colheita, altura de inserção da primeira vagem, altura de inserção da última vagem, grau de acamamento e coloração do tegumento dos grãos. As estimativas dos coeficientes de repetibilidade foram obtidas por três métodos análise de variância, componentes principais e análise estrutural. Sete experimentos possibilitam a identificação de cultivares superiores de feijão em relação às características de produção, de fenologia e de morfologia, com $85 \%$ de exatidão no prognóstico de seu valor real.
\end{abstract}

Palavras-chave: Phaseolus vulgaris L., repetibilidade, seleção, precisão experimental.

\section{ABSTRACT}

The objective of this research was to determine how many evaluations (experiments) were necessary to predict the performance of common bean (Phaseolus vulgaris) cultivars. Fourteen common beans cultivars were evaluated in nine experiments conducted in Santa Maria, in Rio Grande do

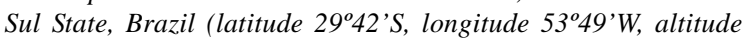
$95 \mathrm{~m}$ ) in agricultural years from 2000/2001 to 2004/2005. The evaluations were constituted by grain yield, number of pods per plant, number of seeds per pod, weight of 100 grains, final population of plants, number of days of the emergency to flowering, number of days of the emergency to harvest, height of first pod insertion, height of the final pod insertion, degree of the down and colour of grain tegument. Repeatability estimations were obtained through three methods variance, structural, and principal component analysis. In conclusion, seven evaluations are sufficient to identify superior genotypes for productive, phenologic and morphologic characteristics of the common beans, with $85 \%$ accuracy of the real value.

Key words: Phaseolus vulgaris L., repeatability, selection, experimental precision.

\section{INTRODUÇÃO}

Nas etapas finais de um programa de melhoramento de plantas, há necessidade de avaliar o desempenho das linhagens frente às inúmeras variações ambientais (locais, anos e épocas), para que seja possível a sua inscrição como cultivar no Serviço Nacional de Proteção de Cultivares (SNPC), no Ministério da Agricultura, Pecuária e Abastecimento (MAPA). Esse é o processo mais trabalhoso e oneroso do programa, pois se estabelece uma rede de ensaios e um posterior estudo de adaptabilidade e de estabilidade - fundamentados na presença de interação genótipo $\mathrm{x}$ ambiente - o que permitirá a identificação de cultivares adequadas para ambientes gerais e/ou específicos de cultivo. Diversas metodologias de análise de

\footnotetext{
${ }^{1}$ Departamento de Ciências Exatas, Faculdade de Ciências Agrárias e Veterinárias (FCAV), Universidade Estadual Paulista (UNESP). Via de Acesso Prof. Paulo Donato Castellane, s/n, 14884-900, Jaboticabal, SP, Brasil. E-mail: cargnelutti@fcav.unesp.br. Autor para correspondência.

${ }^{2}$ Departamento de Fitotecnia, Centro de Ciências Rurais (CCR), Universidade Federal de Santa Maria (UFSM), 97105-900, Santa Maria, RS, Brasil. E-mail: neiadr@smail.ufsm.br.

${ }^{3}$ Curso de Agronomia, UFSM, Santa Maria, RS, Brasil. E-mail: evandrojost@bol.com.br.
} 
adaptabilidade e de estabilidade são disponibilizadas, sendo a escolha fundamentada no número de ambientes e na precisão requerida (CRUZ \& REGAZZI, 1997).

Além da interação genótipo $\mathrm{x}$ ambiente ocorrer entre os locais de uma região, no mesmo ano de cultivo, presença de interação também é esperada em cada local, entre anos e épocas de cultivo. Assim, a análise de adaptabilidade e de estabilidade baseada em experimentos conduzidos em uma rede de ensaios em apenas um ano de cultivo poderá ser pouco eficiente, devido à variabilidade de resposta das linhagens frente às condições ambientais para cada local, de acordo com os anos e épocas de cultivo. $\mathrm{O}$ número de ambientes (experimentos) deve ser o mais abrangente possível entre os locais de uma região e, no mesmo local, deve-se utilizar o maior número de anos e épocas de cultivo.

A inclusão de novos ambientes (locais, anos e épocas) poderá alterar a classificação das linhagens. Portanto, a determinação do número de medições (experimentos) necessárias para a estimativa das diferenças entre as linhagens é particularmente importante na confiabilidade da seleção daquelas de melhor desempenho, por meio das análises de adaptabilidade e de estabilidade.

Não é possível ter-se a previsão das condições ambientais nos próximos anos e épocas de cultivo, mas, por meio dos resultados de experimentos de avaliação de linhagens, em cultivos subseqüentes em um local (anos e épocas), pode-se, baseado em um número mínimo de experimentos, identificar linhagens superiores com certa confiabilidade, independentemente das condições ambientais prevalescentes. Essas estimativas, por meio da análise de repetibilidade, não podem ser extrapoladas para outros locais da rede de ensaios, devido à variabilidade ambiental entre os locais e, dentro de locais, entre os cultivos (anos e épocas). No entanto, é esperada uma proximidade dessas estimativas. Além disso, é esperado um menor número de experimentos para o local com uma variabilidade ambiental menor entre cultivos e vice-versa.

Nos ensaios envolvendo genótipos de feijão (Phaseolus vulgaris L.), avaliados em diferentes ambientes (anos e épocas), é possível estimar os coeficientes de repetibilidade das características de produção, de fenologia e de morfologia, ou seja, a probabilidade de aquele resultado se repetir em avaliações futuras e, também, o número de observações fenotípicas necessárias, de um determinado caráter, que devem ser realizadas em cada indivíduo para que a discriminação (ou seleção) entre as linhagens seja feita com certo grau de confiabilidade e com economia de tempo e de mão-de-obra (CORNACCHIA et al., 1995; CRUZ \& REGAZZI, 1997; PEREIRA et al., 1998; FERREIRA et al., 1999).

O coeficiente de repetibilidade de uma característica pode ser conceituado, estatisticamente, como a correlação entre as medidas em um mesmo indivíduo, cujas avaliações foram repetidas no tempo ou no espaço, sendo que a repetibilidade expressa a proporção da variância total, que é devida às variações proporcionadas pelo genótipo e às alterações permanentes atribuídas ao ambiente comum (ABEYWARDENA, 1972; KEMPTHORNE, 1973; CRUZ \& REGAZZI, 1997). A repetibilidade expressa o valor máximo que a herdabilidade pode atingir, pois representa a proporção da variância fenotípica, que é atribuída às diferenças genéticas, confundidas com os efeitos permanentes que atuam no genótipo. O número de medições necessárias na previsão do valor real do indivíduo é aquele em que os efeitos temporários do ambiente sobre o caráter tendem a se cancelar (CRUZ \& REGAZZI, 1997).

Valores altos de estimativas de repetibilidade para determinado caráter indicam que é viável predizer o valor real do indivíduo, utilizando-se um número relativamente pequeno de medições (CRUZ \& REGAZZI, 1997), ocorrendo o inverso quando a repetibilidade é baixa. Então, o emprego da análise de repetibilidade é uma ferramenta útil para determinar o número de medições (experimentos) para uma correta identificação de cultivares por meio da análise de adaptabilidade e de estabilidade.

Métodos para a obtenção de estimativas de coeficiente de repetibilidade, como o da análise de variância, o dos componentes principais (ABEYWARDENA, 1972; RUTLEDGE, 1974) e o da análise estrutural (MANSOUR et al., 1981) têm sido usados em culturas perenes, como a da seringueira (VASCONCELLOS et al., 1985), a do pinus (CORNACCHIAet al., 1995), a do cupuaçuzeiro (COSTA et al., 1997), a da alfafa (PEREIRA et al., 1998; FERREIRA et al., 1999; SOUZA-SOBRINHO et al., 2004), a do cacau (DIAS \& KAGEYAMA, 1998; CARVALHO, 1999), a do cajueiro-anão precoce (CAVALCANTI et al., 2000), a da aceroleira (LOPES et al., 2001), a do açaizeiro (OLIVEIRA \& FERNANDES, 2001), a do capim-elefante (SHIMOYA et al., 2002), a da mangueira (COSTA, 2003), a do Panicum maximum (CARGNELUTTI FILHO et al., 2004a), a da cana-de-açúcar (SANTOS et al., 2004) e em culturas anuais como a do tomateiro (CARGNELUTTI FILHO et al., 2004b). No entanto, nenhuma referência ao emprego dessa metodologia para a cultura do feijão foi encontrada na literatura. 
O objetivo deste trabalho foi determinar o número de medições (experimentos) necessários à predição do desempenho de cultivares de feijão quanto às características de produção, de fenologia e de morfologia na região da depressão central do Estado do Rio Grande do Sul.

\section{MATERIAL E MÉTODOS}

Foram avaliadas 14 cultivares de feijão ("Carioca", "Diamante Negro", "Guapo Brilhante", "Guateian 6662", "Iapar 44", "Irấ", "Macanudo", "Macotaço", "Minuano", "Pérola", "Rio Tibagi”, "TPS Bionobre", "TPS Bonito" e "TPS Nobre"). Os nove experimentos foram conduzidos em área do Departamento de Fitotecnia da Universidade Federal de Santa Maria, em Santa Maria, Rio Grande do Sul (latitude $29^{\circ} 42^{\prime} \mathrm{S}$, longitude $53^{\circ} 49^{\prime} \mathrm{W}, 95 \mathrm{~m}$ de altitude), nos anos agrícolas 2000/2001, 2001/2002, 2002/2003, 2003/2004 e 2004/2005, em duas épocas de cultivo: safra - semeadura em setembro ou outubro - e safrinha semeadura em janeiro ou fevereiro. Considerou-se, neste estudo, como primeiro experimento o cultivo de safra realizado no ano 2000/2001, como segundo experimento o cultivo de safrinha de 2001, e assim sucessivamente até o nono experimento realizado em cultivo de safra, no ano 2004/2005.

Os nove experimentos foram conduzidos no delineamento em blocos ao acaso, com três repetições. As parcelas foram compostas de quatro fileiras de $4 \mathrm{~m}$ de comprimento, espaçadas de $0,50 \mathrm{~m}$, e a área útil de $3 \mathrm{~m}^{2}$. A densidade de semeadura foi ajustada de acordo com o hábito de crescimento de cada cultivar (CEPEF, 2003).

Avaliaram-se as variáveis produtividade de grãos a $13 \%$ de umidade, número de vagens por planta, número de sementes por vagem, massa de cem grãos, população final de plantas, número de dias da emergência ao florescimento, número de dias da emergência à colheita, altura de inserção da primeira vagem, altura de inserção da última vagem, grau de acamamento (escala de notas entre um a nove, sendo 1 = planta ereta e $9=$ planta acamada) e coloração do tegumento dos grãos de cada cultivar de feijão, em cada experimento. A coloração do tegumento dos grãos foi avaliada logo após a colheita, com colorímetro, utilizando o sistema L-a-b, determinando-se neste estudo os valores de "L".

Realizou-se a análise de variância individual e conjunta dos experimentos e teste $\mathrm{F}$ a $5 \%$ de probabilidade - considerando os efeitos de cultivar e de bloco como aleatórios, e o efeito de ambiente (experimento) fixo - e estimou-se a matriz de coeficientes de correlação genotípica de Pearson entre as variáveis. Realizou-se, também, a análise de variância, a partir da média das repetições, utilizando-se o modelo estatístico reduzido com dois fatores de variação $\left(\mathrm{Y}_{\mathrm{ij}}=\mathrm{m}+\mathrm{C}_{\mathrm{i}}+\mathrm{A}_{\mathrm{j}}\right.$ $+\mathrm{e}_{\mathrm{ij}}$ ), em que, $\mathrm{Y}_{\mathrm{ij}}=$ média da i-ésima cultivar no j-ésimo experimento; $\mathrm{m}=$ média geral $; \mathrm{C}_{\mathrm{i}}=$ efeito aleatório da $\mathrm{i}$ ésima cultivar sob influência do ambiente permanente (experimento) $\left(\mathrm{i}=1,2, \ldots, 14\right.$ cultivar); $\mathrm{A}_{\mathrm{j}}=$ efeito fixo do ambiente temporário no j-ésimo experimento $(\mathrm{j}=1,2, \ldots, 9$ experimento); $\mathrm{e}_{\mathrm{ij}}=$ efeito aleatório que envolve outras causas de variação não incluídas no modelo.

As estimativas dos coeficientes de repetibilidade ( ) foram obtidas pelos métodos da análise de variância (ANOVA), dos componentes principais com base nas matrizes de correlações (CPcor) e de variâncias e covariâncias fenotípicas (CPcov) e da análise estrutural, com base nas matrizes de correlações intraclasse (AEcor) e de variâncias e covariâncias (AEcov). O número mínimo de medições necessárias para predizer o valor real dos indivíduos, com base nos coeficientes de determinação $\left(\mathrm{R}^{2}\right)$ pré-estabelecidos $(0,80,0,85,0,90,0,95$ e 0,99$)$, foi obtido conforme CRUZ \& REGAZZI (1997). As análises estatísticas foram realizadas, utilizando-se o programa computacional GENES(CRUZ, 2001).

\section{RESULTADOS E DISCUSSÃO}

O teste de Bartlett (STEEL et al., 1997) aplicado entre os quadrados médios residuais, da análise individual dos nove experimentos, constatou variâncias residuais heterogêneas $(\mathrm{p}<0,05)$ em relação aos caracteres produtividade de grãos (PROD), número de vagens por planta (NVP), número de sementes por vagem (NSV), massa de cem grãos (MCG), população final de plantas (POP), número de dias da emergência ao florescimento (FLOR), número de dias da emergência à colheita (CICLO), altura de inserção da primeira vagem (A1V), altura de inserção da última vagem (AUV), grau de acamamento (ACA) e coloração do tegumento dos grãos (COR) (Tabelas 1 e 2). Estes resultados indicam que, para a realização adequada da análise de variância conjunta, haveria necessidade de exclusão de experimento(s) com quadrados médios residuais discrepantes, formação de grupos de experimentos com variâncias residuais homogêneas ou ajuste dos graus de liberdade para a interpretação correta dos testes de hipóteses, visando a uma adequada identificação de cultivares por meio da análise de adaptabilidade e de estabilidade. No entanto, para este estudo, a ocorrência dessas variâncias residuais heterogêneas é particularmente importante, pois inclui maior variabilidade ambiental e, conseqüentemente, a 
Tabela 1 - Análise de variância conjunta e análise de variância (modelo reduzido) dos caracteres produtividade de grãos (PROD), número de vagens por planta (NVP), número de sementes por vagem (NSV), massa de cem grãos (MCG) e população final de plantas (POP) de 14 cultivares de feijão, avaliadas em nove experimentos, média, coeficiente de variação experimental $(\mathrm{CVe})$ e genético $(\mathrm{CVg})$, relação entre o maior e menor quadrado médio do erro, valor calculado da estatística do teste de Bartlett $\left(\chi_{\text {calc }}^{2}\right)$ dos quadrados médios do erro entre os experimentos e estimativas dos componentes da variância genotípica $\left(\hat{\boldsymbol{\sigma}}_{\mathrm{g}}\right)$, ambiental $(\hat{\boldsymbol{\sigma}})$ e fenotípica $\left(\hat{\sigma}_{\mathrm{f}}\right)$. Santa Maria-RS, UFSM, 2005.

\begin{tabular}{|c|c|c|c|c|c|c|}
\hline \multirow[b]{3}{*}{ Fonte de variação } & \multirow[b]{3}{*}{ GL } & \multicolumn{5}{|c|}{ Análise de variância conjunta } \\
\hline & & \multicolumn{5}{|c|}{ Quadrado médio $^{(1)}$} \\
\hline & & $\begin{array}{l}\text { PROD } \\
\left(\mathrm{kg} \mathrm{ha}^{-1}\right)\end{array}$ & NVP & NSV & $\begin{array}{c}\text { MCG } \\
(\mathrm{g})\end{array}$ & $\begin{array}{c}\text { POP } \\
\left(\text { plantas } 3 \mathrm{~m}^{-2}\right)\end{array}$ \\
\hline Blocos/Ambiente & 18 & 1516048,92 & 40,85 & 0,39 & 17,14 & 264,55 \\
\hline Cultivares (C) & 13 & $1253487,90 *$ & $82,42 *$ & $5,23 *$ & $550,16 *$ & $831,54 *$ \\
\hline Ambientes (A) & 8 & $21673247,37 *$ & $460,58 *$ & $12,68 *$ & $546,75 *$ & $1288,87 *$ \\
\hline $\mathrm{CxA}$ & 104 & $264300,39 *$ & $15,80 *$ & $0,31^{\mathrm{ns}}$ & $9,12 *$ & $141,47 *$ \\
\hline Resíduo & 234 & 66134,47 & 6,47 & 0,27 & 4,24 & 75,57 \\
\hline Média & & 1409,96 & 11,52 & 4,29 & 19,03 & 56,34 \\
\hline $\mathrm{CVe}(\%)$ & & 18,24 & 22,09 & 12,14 & 10,82 & 15,43 \\
\hline $\operatorname{CVg}(\%)$ & & 14,87 & 14,56 & 9,99 & 23,63 & 9,39 \\
\hline$>\mathrm{QME} /<\mathrm{QME}$ & & 16,47 & 4,06 & 4,59 & 8,41 & 15,17 \\
\hline \multirow[t]{2}{*}{$\chi_{\text {calc }}^{2}$} & & $63,96 *$ & $21,23 *$ & $22,89 *$ & $49,10 *$ & $83,15^{*}$ \\
\hline & & \multicolumn{5}{|c|}{ Análise de variância (modelo reduzido) } \\
\hline & & \multicolumn{5}{|c|}{ Quadrado médio ${ }^{(1)}$} \\
\hline Fonte de variação & GL & $\begin{array}{c}\text { PROD } \\
\left(\mathrm{kg} \mathrm{ha}^{-1}\right)\end{array}$ & NVP & NSV & $\begin{array}{c}\text { MCG } \\
(\mathrm{g})\end{array}$ & $\begin{array}{c}\text { POP } \\
\left(\text { plantas } 3 \mathrm{~m}^{-2}\right)\end{array}$ \\
\hline Ambientes & 8 & 7224415,67 & 153,53 & 4,23 & 182,25 & 429,62 \\
\hline Cultivares & 13 & $417829,30 *$ & $27,47 *$ & $1,74^{*}$ & $183,39 *$ & $277,18^{*}$ \\
\hline Resíduo & 104 & 88100,13 & 5,27 & 0,10 & 3,04 & 47,16 \\
\hline Média & & 1409,96 & 11,52 & 4,29 & 19,03 & 56,34 \\
\hline $\mathrm{CVe}(\%)$ & & 21,05 & 19,93 & 7,44 & 9,16 & 12,19 \\
\hline$\hat{\sigma}_{g}$ & & 36636 & 2,467 & 0,182 & 20,038 & 25,558 \\
\hline$\hat{\sigma}$ & & 88100 & 5,268 & 0,102 & 3,040 & 47,156 \\
\hline$\hat{\sigma}_{\mathrm{f}}$ & & 124736 & 7,736 & 0,284 & 23,079 & 72,714 \\
\hline
\end{tabular}

(1) ns Não-significativo. * Significativo a $5 \%$ de probabilidade pelo teste F.

(2) * Significativo a 5\% de probabilidade pelo teste de Bartlett (quadrados médios residuais heterogêneos).

estimativa do número de experimentos necessários para a identificação de cultivares superiores oferece maior segurança.

A análise de variância conjunta em relação a todos os caracteres - com exceção do número de sementes por vagem - possibilita inferir que uma presença de interação cultivar $\mathrm{x}$ ambiente (experimento) significativa foi obtida, indicando comportamento diferenciado das cultivares nos ambientes, e que a identificação de cultivares de feijão por meio da análise de adaptabilidade e de estabilidade é um procedimento que se justifica. Assim, pode-se afirmar que análises de adaptabilidade e de estabilidade baseadas em apenas uma época de cultivo, mesmo sendo de diversos locais, podem fornecer informações equivocadas, por não considerarem a variabilidade ambiental entre anos e épocas de cultivo dentro de um mesmo local.

$O$ coeficiente de variação experimental da análise de variância conjunta oscilou de 1,86\% (CICLO) a 22,09\% (NVP), enquanto que, na análise de variância por meio do modelo reduzido, variou de 3,09\% (CICLO) a 21,05\% (PROD). De modo geral, esses resultados

Ciência Rural, v.36, n.6, nov-dez, 2006. 
Tabela 2 - Análise de variância conjunta e análise de variância (modelo reduzido) dos caracteres número de dias da emergência ao florescimento (FLOR), número de dias da emergência à colheita (CICLO), altura de inserção da primeira vagem (A1V), altura de inserção da última vagem (AUV), grau de acamamento (ACA) e coloração do tegumento dos grãos (COR) de 14 cultivares de feijão, avaliadas em nove experimentos, média, coeficiente de variação experimental (CVe) e genético (CVg), relação entre o maior e menor quadrado médio do erro, valor calculado da estatística do teste de Bartlett $\left(\chi_{\text {calc }}^{2}\right)$ dos quadrados médios do erro entre os experimentos e estimativas dos componentes da variância genotípica $\left(\hat{\boldsymbol{\sigma}}_{\mathrm{g}}\right)$, ambiental $(\hat{\boldsymbol{\sigma}})$ e fenotípica $\left(\hat{\boldsymbol{\sigma}}_{\mathrm{f}}\right)$. Santa Maria-RS, UFSM, 2005.

\begin{tabular}{|c|c|c|c|c|c|c|c|}
\hline \multirow[b]{3}{*}{ Fonte de variação } & \multirow[b]{3}{*}{ GL } & \multicolumn{6}{|c|}{ Análise de variância conjunta } \\
\hline & & \multicolumn{6}{|c|}{ Quadrado médio ${ }^{(1)}$} \\
\hline & & $\begin{array}{l}\text { FLOR } \\
\text { (dias) }\end{array}$ & $\begin{array}{c}\text { CICLO } \\
\text { (dias) }\end{array}$ & $\begin{array}{l}\text { A1V } \\
(\mathrm{cm})\end{array}$ & $\begin{array}{r}\text { AUV } \\
(\mathrm{cm})\end{array}$ & $\mathrm{ACA}^{(2)}$ & COR \\
\hline Blocos/Ambiente & 18 & 5,87 & 28,91 & 35,07 & 47,16 & 4,82 & 1,18 \\
\hline Cultivares $(\mathrm{C})$ & 13 & $142,45 *$ & $184,34 *$ & $138,26 *$ & $921,91 *$ & $49,38 *$ & $7071,83 *$ \\
\hline Ambientes (A) & 8 & $478,74 *$ & $613,25 *$ & $455,01 *$ & $3271,00 *$ & $62,65 *$ & $79,90 *$ \\
\hline $\mathrm{CxA}$ & 104 & $6,04 *$ & $17,02 *$ & $29,87 *$ & $87,20 *$ & $2,39 *$ & $6,81 *$ \\
\hline Resíduo & 234 & 1,74 & 2,07 & 10,60 & 40,33 & 1,40 & 0,38 \\
\hline Média & & 36,99 & 77,19 & 15,03 & 40,94 & 5,99 & 31,17 \\
\hline $\mathrm{CVe}(\%)$ & & 3,57 & 1,86 & 21,67 & 15,51 & 19,79 & 1,99 \\
\hline $\operatorname{CVg}(\%)$ & & 6,17 & 3,37 & 14,47 & 13,96 & 22,27 & 51,92 \\
\hline$>\mathrm{QME} /<\mathrm{QME}$ & & 3,96 & 6,79 & 7,62 & 8,13 & 5,67 & 4,50 \\
\hline \multirow[t]{2}{*}{$\chi_{\text {calc }}^{2}$} & & $34,15 *$ & $48,11^{*}$ & $46,03^{*}$ & $28,94^{*}$ & $26,07 *$ & $25,32 *$ \\
\hline & & \multicolumn{6}{|c|}{ Análise de variância (modelo reduzido) } \\
\hline & & \multicolumn{6}{|c|}{ Quadrado médio ${ }^{(1)}$} \\
\hline Fonte de variação & GL & $\begin{array}{c}\text { FLOR } \\
\text { (dias) }\end{array}$ & $\begin{array}{c}\text { CICLO } \\
\text { (dias) }\end{array}$ & $\begin{array}{l}\text { A1V } \\
(\mathrm{cm})\end{array}$ & $\begin{array}{l}\text { AUV } \\
(\mathrm{cm})\end{array}$ & $\mathrm{ACA}^{(2)}$ & COR \\
\hline Ambientes & 8 & 159,58 & 204,42 & 151,67 & 1090,33 & 20,88 & 26,63 \\
\hline Cultivares & 13 & $47,48^{*}$ & $61,45^{*}$ & $46,09^{*}$ & $307,30 *$ & $16,46^{*}$ & $2357,28 *$ \\
\hline Resíduo & 104 & 2,01 & 5,67 & 9,96 & 29,07 & 0,80 & 2,27 \\
\hline Média & & 36,99 & 77,19 & 15,03 & 40,94 & 5,99 & 31,17 \\
\hline CVe $(\%)$ & & 3,84 & 3,09 & 21,00 & 13,17 & 14,91 & 4,83 \\
\hline$\sigma_{g}$ & & 5,052 & 6,197 & 4,015 & 30,915 & 1,741 & 261,667 \\
\hline$\hat{\sigma}$ & & 2,014 & 5,675 & 9,956 & 29,068 & 0,796 & 2,270 \\
\hline$\hat{\sigma}_{\mathrm{f}}$ & & 7,067 & 11,872 & 13,971 & 59,983 & 2,537 & 263,937 \\
\hline
\end{tabular}

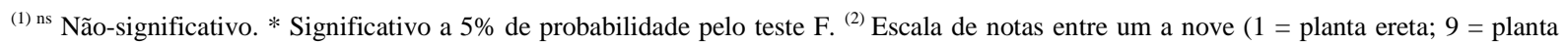
acamada).

(3) * Significativo a 5\% de probabilidade pelo teste de Bartlett (quadrados médios residuais heterogêneos).

indicam uma boa precisão experimental em relação a todos os caracteres (Tabelas 1 e 2). Diferentes valores de coeficiente de variação experimental, em relação à mesma variável, são obtidos em função dos distintos modelos matemáticos utilizados nas análises de variância, sendo o modelo reduzido realizado com a média das repetições.

Os caracteres de produção (PROD, NVP, NSV e POP) e os morfológicos (A1V e AUV) apresentaram relação entre os coeficientes de variação experimental e genético superiores a um, revelando maior efeito ambiental sobre as cultivares, quando comparados aos demais caracteres relativos à produtividade (MCG), à fenologia (FLOR e CICLO) e à morfologia (ACA e COR), cuja relação foi inferior a um, demonstrando que, para esses últimos, há maior variabilidade genética em relação à ambiental (Tabelas 1 e 2). Assim, pode-se inferir que, para a seleção de cultivares superiores, será necessário maior número de experimentos, em relação aos caracteres com maior variabilidade ambiental, e menor para os caracteres com maior variabilidade genética. 
Todos os caracteres produtivos (PROD, NVP, NSV, MCG e POP), fenológicos (FLOR e CICLO) e morfológicos (A1V, AUV, ACA e COR) apresentaram efeito de cultivares significativo, indicando a possibilidade de identificação de cultivares superiores por causa da heterogeneidade do germoplasma avaliado (Tabelas 1 e 2).

A maioria das variáveis correlaciona-se linearmente, indicando possibilidade de seleção de cultivares superiores, de modo indireto, mediante características que apresentem maior coeficiente de repetibilidade, e exigindo, conseqüientemente, um menor número de medições para predizer o valor real de uma determinada característica (Tabela 3).

Os coeficientes de determinação $\left(R^{2}\right)$ associados às estimativas dos coeficientes de repetibilidade ( $\hat{r}$ ) foram iguais ou superiores a $78,46 \%$ - independentemente do método de estimativa de $\hat{\mathrm{r}}$ e do caráter - indicando que nove experimentos possibilitam detectar diferenças genotípicas com $78,46 \%$ ou mais de certeza na predição do valor real da cultivar (Tabela 4).

Independentemente do caráter e do método, a magnitude da estimativa do coeficiente de repetibilidade ( $\hat{\mathbf{r}}$ ) oscilou entre 0,29 a 1,00 . De modo geral, menores estimativas de $\hat{\mathrm{r}}$ foram obtidas em relação aos caracteres produtivos (PROD, NVP, NSV e POP), fenológicos (CICLO) e morfológicos (A1V e AUV), e maiores estimativas para as características de produção (MCG), fenológicas (FLOR) e morfológicas (ACAe COR) (Tabela 4). Menores valores de indicam necessidade de maior número de experimentos para discriminação de cultivares e vice-versa. Esses resultados, provavelmente, podem ser explicados pelo maior e menor grau de variabilidade ambiental e genética.

O método dos componentes principais, baseado na matriz de covariância (CPcov), apresentou maiores valores de coeficientes de repetibilidade em sete (PROD, NVP, NSV, MCG, A1V, ACA e COR) das onze características. Já, em relação às demais variáveis (POP, FLOR, CICLO e AUV), maior valor foi observado no método dos componentes principais, com base na matriz de correlações (CPcor). Predomínio de maiores valores de coeficientes de repetibilidade do método CPcov em relação aos demais foi obtido em caracteres de cajueiro-anão precoce (CAVALCANTI et al., 2000), de Panicum maximum (CARGNELUTTI FILHO et al., 2004a) e de tomateiro (CARGNELUTTI FILHO et al., 2004b).

Por outro lado, de maneira geral, as estimativas dos coeficientes de repetibilidade obtidas pelos métodos da análise de variância (ANOVA) e da análise estrutural, com base na matriz de correlações intraclasse (AEcor) e na matriz de variâncias e covariâncias (AEcov), apresentaram valores inferiores para todas as variáveis. Esses resultados corroboram com os de ABEYWARDENA (1972), ao relatar que a estimativa mais adequada do coeficiente de repetibilidade, quando os genótipos apresentam comportamento cíclico ao longo das avaliações em relação ao caráter estudado, é aquela obtida pelo método baseado nos componentes principais. Em muitas espécies, a produção ocorre de forma oscilante, havendo grande variabilidade de produção entre experimentos. Como este efeito, pode variar de maneira

Tabela 3 - Matriz de coeficientes de correlação genotípica de Pearson entre os caracteres produtividade de grãos (PROD), número de vagens por planta (NVP), número de sementes por vagem (NSV), massa de cem grãos (MCG), população final de plantas (POP), número de dias da emergência ao florescimento (FLOR), número de dias da emergência à colheita (CICLO), altura de inserção da primeira vagem (A1V), altura de inserção da última vagem (AUV), grau de acamamento (ACA) e coloração do tegumento dos grãos (COR) de 14 cultivares de feijão, avaliadas em nove experimentos. ${ }^{(1)}$ Santa Maria-RS, UFSM, 2005.

\begin{tabular}{|c|c|c|c|c|c|c|c|c|c|c|}
\hline Caráter & NVP & NSV & $\mathrm{MCG}$ & POP & FLOR & CICLO & A1V & AUV & $\mathrm{ACA}^{(2)}$ & COR \\
\hline PROD (kg ha $\left.{ }^{-1}\right)$ & $0,69 * *$ & $-0,20 * *$ & $0,31 * *$ & $0,02^{\mathrm{ns}}$ & $-0,50 * *$ & $-0,61 * *$ & $-0,68 * *$ & $-0,43 * *$ & $-0,49 * *$ & $0,04^{\mathrm{ns}}$ \\
\hline NVP & & $0,34 * *$ & $-0,37 * *$ & $-0,31 * *$ & $0,03^{\mathrm{ns}}$ & $-0,29 * *$ & $-0,54 * *$ & $-0,24 * *$ & $0,12 *$ & $-0,40 * *$ \\
\hline NSV & & & $-0,94 * *$ & $-0,25 * *$ & $0,83 * *$ & $0,69 * *$ & $0,43 * *$ & $0,60 * *$ & $0,40 * *$ & $-0,73 * *$ \\
\hline $\operatorname{MCG}(g)$ & & & & $0,25 * *$ & $-0,82 * *$ & $-0,60 * *$ & $-0,36 * *$ & $-0,46 * *$ & $-0,58 * *$ & $0,71 * *$ \\
\hline POP (plantas $3 \mathrm{~m}^{-2}$ ) & & & & & $-0,50 * *$ & $-0,36 * *$ & $-0,10^{\mathrm{ns}}$ & $-0,48 * *$ & $-0,62 * *$ & $-0,32 * *$ \\
\hline FLOR (dias) & & & & & & $0,88^{* *}$ & $0,70 * *$ & $0,79 * *$ & $0,65 * *$ & $-0,31 * *$ \\
\hline CICLO (dias) & & & & & & & $0,91 * *$ & $0,86 * *$ & $0,43 * *$ & $-0,16^{* *}$ \\
\hline $\mathrm{A} 1 \mathrm{~V}(\mathrm{~cm})$ & & & & & & & & $0,89 * *$ & $0,30 * *$ & $-0,08^{\mathrm{ns}}$ \\
\hline AUV (cm) & & & & & & & & & $0,46^{* *}$ & $-0,12 *$ \\
\hline $\mathrm{ACA}^{(2)}$ & & & & & & & & & & $-0,09^{\mathrm{ns}}$ \\
\hline
\end{tabular}

${ }^{(1)}$ ns Não-significativo. **, * significativo a 1 e $5 \%$ de probabilidade, respectivamente, pelo teste t, com 376 graus de liberdade. ${ }^{(2)}$ Escala de notas entre um a nove $(1=$ planta ereta; 9 = planta acamada $)$. 
Tabela 4 - Estimativas dos coeficientes de repetibilidade $(\hat{\mathbf{r}})$, dos coeficientes de determinação $\left(\mathrm{R}^{2}\right)$ e do número de medições ou experimentos $\left(\eta_{\mathrm{o}}\right)^{(4)}$ associado a diferentes coeficientes de determinação $\left(\mathrm{R}^{2}\right)$ dos caracteres produtividade de grãos (PROD), número de vagens por planta (NVP), número de sementes por vagem (NSV), massa de cem grãos (MCG), população final de plantas (POP), número de dias da emergência ao florescimento (FLOR), número de dias da emergência à colheita (CICLO), altura de inserção da primeira vagem (A1V), altura de inserção da última vagem (AUV), grau de acamamento (ACA) e coloração do tegumento dos grãos (COR) de 14 cultivares de feijão, avaliadas em nove experimentos, considerando diferentes métodos. Santa Maria-RS, UFSM, 2005.

\begin{tabular}{|c|c|c|c|c|c|c|c|c|c|c|c|c|}
\hline Método ${ }^{(1)}$ & Estimativas & PROD & NVP & NSV & MCG & POP & FLOR & CICLO & A1V & AUV & $\mathrm{ACA}^{(3)}$ & COR \\
\hline \multirow[t]{7}{*}{ ANOVA } & $\hat{\mathrm{r}}$ & 0,29 & 0,32 & 0,64 & 0,87 & 0,35 & 0,72 & 0,52 & 0,29 & 0,52 & 0,69 & 0,99 \\
\hline & $\mathrm{R}^{2}(\%)$ & 78,91 & 80,83 & 94,15 & 98,34 & 82,99 & 95,76 & 90,77 & 78,40 & 90,54 & 95,16 & 99,90 \\
\hline & $\eta_{0}\left(R^{2}=0,80\right)$ & 10 & 9 & 2 & 0,6 & 7 & 2 & 4 & 10 & 4 & 2 & 0,0 \\
\hline & $\eta_{\mathrm{o}}\left(\mathrm{R}^{2}=0,85\right)$ & 14 & 12 & 3 & 1 & 10 & 2 & 5 & 14 & 5 & 3 & 0,0 \\
\hline & $\eta_{\mathrm{o}}\left(\mathrm{R}^{2}=0,90\right)$ & 22 & 19 & 5 & 1 & 17 & 4 & 8 & 22 & 8 & 4 & 0,1 \\
\hline & $\eta_{\mathrm{o}}\left(\mathrm{R}^{2}=0,95\right)$ & 46 & 41 & 11 & 3 & 35 & 8 & 17 & 47 & 18 & 9 & 0,2 \\
\hline & $\eta_{\mathrm{o}}\left(\mathrm{R}^{2}=0,99\right)$ & 238 & 211 & 55 & 15 & 183 & 39 & 91 & 246 & 93 & 45 & 0,9 \\
\hline \multirow[t]{7}{*}{$\mathrm{CP}(\operatorname{cov})$} & $\hat{\mathbf{r}}$ & 0,55 & 0,45 & 0,67 & 0,90 & 0,47 & 0,73 & 0,64 & 0,48 & 0,54 & 0,73 & 1,00 \\
\hline & $\mathrm{R}^{2}(\%)$ & 91,65 & 88,22 & 94,87 & 98,76 & 89,04 & 96,09 & 94,20 & 89,19 & 91,50 & 96,07 & 99,95 \\
\hline & $\eta_{\mathrm{o}}\left(\mathrm{R}^{2}=0,80\right)$ & 3 & 5 & 2 & 0,5 & 4 & 1 & 2 & 4 & 3 & 1 & 0,0 \\
\hline & $\eta_{0}\left(R^{2}=0,85\right)$ & 5 & 7 & 3 & 1 & 6 & 2 & 3 & 6 & 5 & 2 & 0,0 \\
\hline & $\eta_{0}\left(R^{2}=0,90\right)$ & 7 & 11 & 4 & 1 & 10 & 3 & 5 & 10 & 8 & 3 & 0,0 \\
\hline & $\eta_{0}\left(R^{2}=0,95\right)$ & 16 & 23 & 9 & 2 & 21 & 7 & 11 & 21 & 16 & 7 & 0,1 \\
\hline & $\eta_{\mathrm{o}}\left(\mathrm{R}^{2}=0,99\right)$ & 81 & 119 & 48 & 11 & 110 & 36 & 55 & 108 & 83 & 36 & 0,5 \\
\hline \multirow[t]{7}{*}{$\mathrm{CP}($ cor $)$} & $\hat{\mathbf{r}}$ & 0,34 & 0,39 & 0,67 & 0,89 & 0,48 & 0,75 & 0,65 & 0,37 & 0,63 & 0,71 & 1,00 \\
\hline & $\mathrm{R}^{2}(\%)$ & 82,48 & 85,17 & 94,73 & 98,70 & 89,12 & 96,49 & 94,24 & 83,94 & 93,90 & 95,73 & 99,95 \\
\hline & $\eta_{\mathrm{o}}\left(\mathrm{R}^{2}=0,80\right)$ & 8 & 6 & 2 & 0,5 & 4 & 1 & 2 & 7 & 2 & 2 & 0,0 \\
\hline & $\eta_{0}\left(R^{2}=0,85\right)$ & 11 & 9 & 3 & 1 & 6 & 2 & 3 & 10 & 3 & 2 & 0,0 \\
\hline & $\eta_{0}\left(R^{2}=0,90\right)$ & 17 & 14 & 5 & 1 & 10 & 3 & 5 & 15 & 5 & 4 & 0,0 \\
\hline & $\eta_{0}\left(R^{2}=0,95\right)$ & 36 & 30 & 10 & 2 & 21 & 6 & 10 & 33 & 11 & 8 & 0,1 \\
\hline & $\eta_{\mathrm{o}}\left(\mathrm{R}^{2}=0,99\right)$ & 189 & 155 & 50 & 12 & 109 & 32 & 54 & 170 & 58 & 40 & 0,5 \\
\hline \multirow[t]{7}{*}{$\mathrm{AE}(\operatorname{cov})$} & $\hat{\mathrm{r}}$ & 0,29 & 0,32 & 0,64 & 0,87 & 0,35 & 0,72 & 0,52 & 0,29 & 0,52 & 0,69 & 0,99 \\
\hline & $\mathrm{R}^{2}(\%)$ & 78,91 & 80,83 & 94,15 & 98,34 & 82,99 & 95,76 & 90,77 & 78,40 & 90,54 & 95,16 & 99,90 \\
\hline & $\eta_{0}\left(R^{2}=0,80\right)$ & $-^{-(2)}$ & - & - & & - & - & - & - & - & & \\
\hline & $\eta_{0}\left(R^{2}=0,85\right)$ & - & - & - & & - & - & - & - & - & & \\
\hline & $\eta_{0}\left(R^{2}=0,90\right)$ & - & - & - & & - & - & - & - & - & & \\
\hline & $\eta_{0}\left(R^{2}=0,95\right)$ & - & - & - & & - & - & - & - & - & & \\
\hline & $\eta_{\mathrm{o}}\left(\mathrm{R}^{2}=0,99\right)$ & - & - & - & & - & - & - & - & - & & \\
\hline \multirow[t]{7}{*}{$\mathrm{AE}(\mathrm{cor})$} & $\hat{\mathrm{r}}$ & 0,30 & 0,29 & 0,66 & 0,89 & 0,36 & 0,75 & 0,63 & 0,36 & 0,61 & 0,71 & 1,00 \\
\hline & $\mathrm{R}^{2}(\%)$ & 79,39 & 78,46 & 94,55 & 98,69 & 83,57 & 96,38 & 93,95 & 83,22 & 93,26 & 95,66 & 99,95 \\
\hline & $\eta_{0}\left(R^{2}=0,80\right)$ & 9 & 10 & 2 & 0,5 & 7 & 1 & 2 & 7 & 3 & 2 & 0,0 \\
\hline & $\eta_{\mathrm{o}}\left(\mathrm{R}^{2}=0,85\right)$ & 13 & 14 & 3 & 1 & 10 & 2 & 3 & 10 & 4 & 2 & 0,0 \\
\hline & $\eta_{\mathrm{o}}\left(\mathrm{R}^{2}=0,90\right)$ & 21 & 22 & 5 & 1 & 16 & 3 & 5 & 16 & 6 & 4 & 0,0 \\
\hline & $\eta_{0}\left(R^{2}=0,95\right)$ & 44 & 47 & 10 & 2 & 34 & 6 & 11 & 34 & 12 & 8 & 0,1 \\
\hline & $\eta_{o}\left(R^{2}=0,99\right)$ & 231 & 245 & 51 & 12 & 175 & 33 & 57 & 180 & 64 & 40 & 0,5 \\
\hline
\end{tabular}

${ }^{(1)}$ ANOVA: análise de variância; $\mathrm{CP}(\mathrm{cov})$ : componentes principais das variâncias e covariâncias; $\mathrm{CP}(\mathrm{cor})$ : componentes principais das correlações; $\mathrm{AE}(\mathrm{cov})$ : análise estrutural da covariância; AE(cor): análise estrutural da correlação. ${ }^{(2)}$ Estimativas não calculadas por este método. ${ }^{(3)}$ Escala de notas entre um a nove $\left(1=\right.$ planta ereta; $9=$ planta acamada). ${ }^{(4)}$ Estimativas menores que um devem ser interpretadas como um. 
e intensidade diferentes entre os genótipos. A análise de variância, utilizada para estimar o coeficiente de repetibilidade, pode não eliminar este componente adicional do erro experimental, e, conseqüentemente, o estimador de repetibilidade estaria subestimado (CRUZ \& REGAZZI, 1997).

Na média das características, o coeficiente de repetibilidade, obtido pelos métodos ANOVA, CPcov, CPcor, AEcov e AEcor, foi, respectivamente, $0,56,0,65,0,63,0,56$ e 0,60 e o coeficiente de determinação foi $89,61 \%, 93,59 \%, 92,22 \%, 89,61 \%$ e $90,94 \%$, confirmando a necessidade de um menor número de experimentos pelo método CPcov (CARGNELUTTIFILHO et al., 2004a; CARGNELUTTI FILHO et al., 2004b). Os valores altos do coeficiente de repetibilidade indicam regularidade da superioridade das cultivares de um experimento para outro e, conseqüentemente, necessidade de menor número de experimentos para realizar a identificação de uma cultivar superior. Além disso, considerando que algumas dessas características estão correlacionadas linearmente entre si, ao nível de $1 \%$ de probabilidade (Tabela 3), a seleção indireta de linhagens superiores seria uma alternativa adequada.

Geralmente, a produtividade de grãos é a principal característica considerada na seleção de novas cultivares de feijão. Assim, considerando o método dos componentes principais, baseado na matriz de covariância (CPcov), que apresentou maior coeficiente de repetibilidade $(0,55)$, haveria necessidade de 81 experimentos para afirmar-se, com $99 \%$ de precisão, a superioridade de uma determinada cultivar para as condições da depressão central do Estado do Rio Grande do Sul. Essa informação comprova a forte atuação do ambiente na expressão dessa característica e a dificuldade do programa de melhoramento na fase final de avaliação de cultivares. Do ponto de vista prático, a condução desse grande número de experimentos em um mesmo local é praticamente inviável, pela alta demanda de custo, pessoal, tempo e mão-de-obra. Além disso, após a realização de 81 experimentos, é bem possível que linhagens superiores às avaliadas já tenham sido desenvolvidas. No entanto, é possível identificar linhagens superiores para um local com menor número de medições (experimentos), porém a precisão dessa inferência é menor, significando que a linhagem selecionada poderá não ser a melhor.

Em outro extremo, em relação à COR, apesar da interação cultivar $\mathrm{x}$ ambiente ser significativa, apenas um experimento é suficiente para selecionar linhagens, quanto à coloração do tegumento, com 99\% de exatidão. Fatores como: a variância entre cultivares estimada pelo quadrado médio do erro ser $1.038,44$ vezes maior que a variância da interação cultivar $\mathrm{x}$ ambiente; a variância genotípica ser 115,3 vezes superior à variância ambiental; o alto coeficiente de repetibilidade $(0,99)$ e ser um caractere qualitativo explicam, de maneira geral, a maior variabilidade genética em relação à ambiental, facilitando a seleção de linhagens quanto a esta característica.

Pelo método CPcov, para estimar o coeficiente de repetibilidade, pode-se identificar cultivares superiores, com precisão de $85 \%$, com até sete experimentos, quanto às características relativas à produtividade (PROD, NVP, NSV, MCG e POP), até três experimentos em relação às características fenológicas (FLOR e CICLO) e até seis experimentos para características morfológicas (A1V, AUV, ACA e COR) (Tabela 4). Sendo assim, sete experimentos são suficientes para identificar cultivares superiores de feijão em relação a características produtivas, fenológicas e morfológicas, com $85 \%$ de precisão.

\section{CONCLUSÃO}

Na região da depressão central do Estado do Rio Grande do Sul, sete experimentos são suficientes para identificar cultivares de feijão superiores em relação às características de produção, de fenologia e de morfologia, com $85 \%$ de exatidão no prognóstico de seu valor real.

\section{REFERÊNCIAS}

ABEYWARDENA, V. An application of principal component analysis in genetics. Journal of Genetics, v.61, p.27-51, 1972.

CARGNELUTTI FILHO, A. et al. Análise de repetibilidade de caracteres forrageiros de genótipos de Panicum maximum, avaliados com e sem restrição solar. Ciência Rural, v.34, p.723-729, 2004a.

CARGNELUTTI FILHO, A. et al. Número de colheitas e comparação de genótipos de tomateiro cultivados em estufa de plástico. Pesquisa Agropecuária Brasileira, v.39, p.953959, 2004b.

CARVALHO, C.G.P. Repetibilidade e seleção de híbridos de cacaueiro. 1999. 177f. Tese (Doutorado em Genética e Melhoramento) - Universidade Federal de Viçosa, Viçosa.

CAVALCANTI, J.J.V. et al. Repetibilidade de caracteres de produção e porte da planta em clones de cajueiro-anão precoce Pesquisa Agropecuária Brasileira, v.35, p.773-777, 2000.

CEPEF. Indicações técnicas para o cultivo de feijão no Rio Grande do Sul. Passo Fundo: UPF, 2003. 149p.

CORNACCHIA, G. et al. Estimativa do coeficiente de repetibilidade para características fenotípicas de procedências de Pinus tecunumanii (Schw.) Eguiluz \& Perry e Pinus caribaea var. hondurensis Barret \& Golfari. Revista Árvore, v.19, p.333-345, 1995.

Ciência Rural, v.36, n.6, nov-dez, 2006. 
COSTA, J.G. Estimativas de repetibilidade de alguns caracteres de produção em mangueira. Ciência Rural, v.33, p.263-266, 2003 .

COSTA, J.G. et al. Estimativas de repetibilidade de características de frutos de cupuaçuzeiro no Estado do Acre. Revista Brasileira de Fruticultura, v.19, p.313-318, 1997.

CRUZ, C.D. Programa genes: versão Windows: aplicativo computacional em genética e estatística. Viçosa: UFV, 2001. $648 \mathrm{p}$.

CRUZ, C.D.; REGAZZI, A.J. Modelos biométricos aplicados ao melhoramento genético. 2.ed. Viçosa: UFV, 1997. 390p.

DIAS, L.A.S.; KAGEYAMA, P.Y. Repeatibility and minimum harvest period of cacao (Theobroma cacao L.) jn southern Bahia. Euphytica, v.102, p.29-35, 1998.

FERREIRA, R.P. et al. Avaliação de cultivares de alfafa e estimativas de repetibilidade de caracteres forrageiros. Pesquisa Agropecuária Brasileira, v.34, p.995-1002, 1999.

KEMPTHORNE, O. An introduction to genetic statistics. 2.ed. Ames: Iowa State University, 1973. 545p.

LOPES, R. et al. Repetibilidade de características do fruto de aceroleira. Pesquisa Agropecuária Brasileira, v.36, p.507513,2001

MANSOUR, H. et al. Estimators of repeatability. Theoretical and Applied Genetics, v.60, p.151-156, 1981.
OLIVEIRA, M.S.P.; FERNANDES, G.L.C. Repetibilidade de caracteres do cacho de açaizeiro nas condições de Belém-PA. Revista Brasileira Fruticultura, v.23, p.613-616, 2001.

PEREIRA, A.V. et al. Comportamento de alfafa cv. Crioula de diferentes origens e estimativas dos coeficientes de repetibilidade para caracteres forrageiros. Revista Brasileira de Zootecnia, v.27, p.686-690, 1998.

RUTLEDGE, J.J. A scaling which removes bias of Abeywardena's estimator of repeatability. Journal of Genetics, v.61, p.247$250,1974$.

SANTOS, M.S.M. et al. Repetibilidade de características agroindustriais em cana-de-acúcar. Pesquisa Agropecuária Brasileira, v.39, p.301-306, 2004.

SHIMOYA, A. et al. Repetibilidade de características forrageiras do capim-elefante. Scientia Agricola, v.59, p.227-234, 2002.

SOUZA-SOBRINHO, F. et al. Estimativas de repetibilidade para produção de matéria seca em alfafa. Ciência Rural, v.34, p.531-537, 2004.

STEEL, R.G.D. et al. Principles and procedures of statistics a biometrical approach. 3.ed. Nova York: McGraw-Hill, 1997. 666p

VASCONCELLOS, M.E.C. et al. Métodos de estimação do coeficiente de repetibilidade no melhoramento da seringueira. Pesquisa Agropecuária Brasileira, v.20, p.433-437, 1985. 